Mots. Les langages du politique

$71 \mid 2003$

Mondialisation(S)

\title{
Emmanuelle Danblon, Rhétorique et rationalité. Essai sur l'émergence de la critique et de la persuasion
}

Dominique DESMARCHELIER

\section{(2) OpenEdition \\ Journals}

Édition électronique

URL : https://journals.openedition.org/mots/8783

DOI : $10.4000 /$ mots. 8783

ISSN : 1960-6001

Éditeur

ENS Éditions

\section{Édition imprimée}

Date de publication : 1 mars 2003

Pagination : 197-199

ISBN : 2-84788-027-5

ISSN : 0243-6450

Référence électronique

Dominique DESMARCHELIER, «Emmanuelle Danblon, Rhétorique et rationalité. Essai sur l'émergence de la critique et de la persuasion », Mots. Les langages du politique [En ligne], 71 | 2003, mis en ligne le 06 mai 2008, consulté le 23 avril 2022. URL : http://journals.openedition.org/mots/8783 ; DOI : https:// doi.org/10.4000/mots.8783

\section{(C) ENS Éditions}


Emmanuelle DANBLON, 2002, Rhétorique et rationalité. Essai sur l'émergence de la critique et de la persuasion, Bruxelles, Éditions de l’Université de Bruxelles, 264 p.

Il est des livres, comme certains quatuors de Haydn, dont on ne sort pas indemne. L'ouvrage d'E. Danblon appartient à cette catégorie. Le pari de cette jeune chercheuse belge était pourtant risqué. Vouloir en effet réconcilier la rhétorique et le naturalisme en établissant un parallèle entre les formes traditionnelles du raisonnement (induction, abduction et déduction) et le développement de nos capacités de raisonnement, ne correspond pas à la tendance la plus en vogue dans les études portant sur l'argumentation.

Avec rigueur dans la démonstration, force dans la persuasion et volonté d'illustrer sa démarche par des exemples empruntés aussi bien à l'argumentation politique (Valéry Giscard d'Estaing et son souvenir d'enfance), qu'au genre judiciaire (l'enfant à la casquette dans le procès Barbie), l'auteure nous invite à la suivre pas à pas dans un raisonnement solide et bien étayé. Le parcours s'effectue en trois étapes.

Le rappel, dans un premier temps, des différents rapports qu'entretiennent raisonnement et rationalité nous conduit à un examen de la notion d'induction et aux différentes attitudes épistémologiques (pessimisme, autoritarisme et rationalisme critique) qui l'ont caractérisée. Cette première partie fournit également l'occasion de mettre en perspective, l'évidence et la certitude si chères à Wittgenstein. Cette mise en place épistémologique permet à $E$. Danblon d'introduire une généalogie de l'induction, allant de la mimesis (l'évidence), au langage oral (la parole proverbiale) pour aboutir au langage écrit (l'induction).

La deuxième étape s'attache à décrire la caractère rationnel de la rhétorique. Jouant Aristote contre Platon, l'auteure souligne que «la notion de vraisemblable, qui s'avérait suspecte chez Platon, car trop voisine du mensonge, se trouve valorisée chez Aristote, qui y voit un indice de la vérité» p. 59. Un examen de l'argumentation mise en œuvre dans les trois genres définis par Aristote, nous rappelle le rôle central de la qualification du fait conduisant à la sentence dans le genre judiciaire, de l'élaboration du conseil dans le délibératif et la place de l'amplification dans l'épidictique. L'exemple du procès de Klaus Barbie illustre le cas où la société est amenée à aménager la loi, " non pas face aux faits, mais face au mythe ». Ceci conduit à une interrogation sur l'origine des normes établies par la société (fondement même des genres judiciaires et délibératifs), et à leur substrat éthique. E. Danblon revient ensuite sur une technique argumentative largement décrite dans le Traité de l'argumentation de Perelman et 
Olbrechts-Tyteca (1958-1998): la dissociation des notions. Cette dernière a pour fonction essentielle de permettre l'argumentabilité des normes. Lorsqu'une «notion sur laquelle tout le monde s'accorde, mais qui, une fois confrontée à un cas particulier, conduit à des incohérences [...]» (p. 121). Constatant que les auteurs du Traité n'ont jamais appliqué cette notion au genre judiciaire ni au droit, E. Danblon lui substitue l'Esprit contre la Lettre. Là encore, un exemple fort pertinent vient étayer son exposé. Le procès du tortionnaire nazi Adolf Eichmann, à Jérusalem, met clairement en évidence qu' «en termes strictement légaux, un tribunal classique n'aurait pas pu juger les actes d'Eichmann» (p. 127). La défense de ce fonctionnaire zélé reposait sur un principe: "obéissance et rigueur dans l'application des tâches qui lui étaient imparties» (p. 125). Sa responsabilité personnelle se trouvait du même coup diluée dans un crime collectif. «Les décisions prises par Eichmann avaient quelque chose de polyphonique (au sens de Ducrot 1984)» (p. 126). Contre la Lettre de la loi, qui reconnait le principe d'obéissance à une autorité, reste alors «l'éloge de la désobéissance. L'usage du terme éloge, profondément ancré dans le genre épidictique, montre que les auteurs veulent invoquer des notions éthiques» (p. 128) permettant de réévaluer le principe d'obéissance.

La troisième partie de l'ouvrage, sans doute la plus audacieuse au plan scientifique (donc, celle qui suscitera le plus de controverses), propose un modèle naturaliste de la raison rhétorique. Se fondant sur la tripartition du signe établie par Peirce (icone, indice symbole), l'auteure souhaite «étayer et affiner l'hypothèse de la généalogie du signe en la replaçant dans un cadre cognitif et social qu'elle propose d'assigner à la rhétorique»(p. 156). Elle élabore ainsi plusieurs tableaux, mettant en relation les types de signes, les formes du langage et les modes épistémiques. À l'icône correspondent la mimesis et le mode de l'évidence sensible. À l'indice sont associés le langage oral et la pensée mythique. Enfin, c'est au stade du symbole qu'est maitrisé le langage écrit et la pensée scientifique. On pourrait certes contester cette division, et notamment invoquer que le stade symbolique est bien présent dès le langage oral, qui, comme plus tard l'écrit, repose sur l'arbitraire du signe (et donc la convention). Dire que l'oral relève du mode indiciel, peut donc paraitre réducteur, mais là encore l'auteure met en avant les travaux de psycholinguistes tendant à montrer que l'enfant, avant 6 ans, n'a pas véritablement accès à toute la dimension métaphorique du langage (figures du discours, ironie) car la conscience réflexive sur le langage n'est possible qu'avec l'écrit. 
Après un passage important sur le rôle de la catégorisation qui permet de donner du sens au monde, la fin de l'ouvrage est consacrée à la mise en relation de cette faculté de catégorisation sémiotique avec la démarche inférentielle elle-même. Fidèle à sa volonté de synthétiser et donc de mettre ensemble, l'auteure rapproche ainsi l'icône et la simple occurrence, l'indice et l'abduction, le symbole et l'induction.

Voilà un ouvrage fort, ambitieux, qui interroge, dérange, peut même irriter nos certitudes, mais repose toujours sur un progression argumentée, étayée d'analyses dont l'exemplarité est incontestable.

Dominique Desmarchelier 